\title{
Role of clinical judgment and tissue harmonic imaging ultrasonography in diagnosis of paediatric acute appendicitis
}

\author{
Ossama Zakaria ${ }^{1,2^{*}}$, Tamer A Sultan ${ }^{3}$, Tarek H Khalii ${ }^{4}$ and Tamer Wahba ${ }^{5}$
}

\begin{abstract}
Background: Appendicitis is the most common surgical emergency in children; yet, diagnosis of equivocal presentations continues to challenge clinicians.

Aim: The objective of this study was to investigate the hypothesis that the use of a modified clinical practice and harmonic ultrasonographic grading scores (MCPGS) may improve the accuracy in diagnosing acute appendicitis in the pediatric population.
\end{abstract}

\section{Patients \& Methods}

Main outcome measures: Sensitivity, specificity, and accuracy of the modified scoring system. Five hundred and thirty patients presented with suspected diagnosis of acute appendicitis during the period from December 2000 to December 2009 were enrolled in this study. Children's data that have already been published of those who presented with suspected diagnosis of acute appendicitis- to whom a special clinical practice grading scores (CPGS) incorporating clinical judgment and results of gray scale ultrasonography (US) was applied- were reviewed and compared to the data of 265 pediatric patients with equivocal diagnosis of acute appendicitis (AA), to whom a modified clinical practice grading scores (MCPGS) was applied. Statistical analyses were carried out using Z test for comparing 2 sample proportions and student's $t$-test to compare the quantitative data in both groups. Sensitivity and specificity for the 2 scoring systems were calculated using Epi-Info software.

Results: The Number of appendectomies declined from 200 (75.5\%) in our previous CPGS to 187 (70.6\%) in the MCPGS $(P>0.05)$.

Specificity was significantly higher when applying MCPGS (90.7\%) in this study compared to $70.47 \%$ in our previous work when CPGS was applied $(P<0.01)$. Furthermore, the positive predictive value (PPV) was significantly higher $(95.72 \%)$ than in our previous study (82.88\%), $(P<0.01)$. Overall agreement (accuracy) of MCPGS was 96.98\%. Kappa = $0.929(P<0.001)$. Negative predictive power was 100\%. And the Overall agreement (accuracy) was $96.98 \%$.

Conclusions: MCPGS tends to help in reduce the numbers of avoidable and unnecessary appendectomies in suspected cases of pediatric acute appendicitis that may help in saving hospital resources.

Keywords: Acute appendicitis in Children, Tissue Harmonic Imaging (THI), Ultrasound scan, Appendicitis clinical score

\footnotetext{
* Correspondence: ossamaz2004@yahoo.com

${ }^{1}$ Division of Pediatric Surgery, Departments of Surgery, Faculty of Medicine,

Suez Canal University, Ismailia, Egypt

Full list of author information is available at the end of the article
} 


\section{Introduction}

Certainty of clinical diagnosis is the most challenging task in clinical practice. It is relatively straight forward to look up the treatment once a correct diagnosis has been made. A single perfect diagnostic test for acute appendicitis does not exist [1-3].

Despite the number of algorithms and diagnostic tests available, about $20 \%$ of patients with appendicitis are misdiagnosed [3-9].

Presence of normal appendix ranges from $5-25 \%$ out of suspected cases of acute appendicitis [5,10-13]. Negative appendectomies were thought to be relatively harmless; nevertheless, they result in considerable unnecessary clinical and economic costs [14]. Even despite the uncertainty of diagnosis, appendicitis demands prompt treatment in order not to be neglected and misdiagnosed leading to progression of the disease with its associated morbidity and mortality that may include the risk of perforation which happens in approximately one third of the cases $[5,15,16]$.

In an attempt to improve diagnosis, attention has turned to radiological imaging. The use of ultrasound scan (US) has been advocated as the readily available simple and fast imaging modality particularly in thin patients and children. A normal appendix is not frequently observed using gray-scale US $[17,18]$. On the other hand Harmonic imaging (HI) increases the contrast and spatial resolution resulting in artifact-free images, and has been shown to significantly improve abdominal ultrasonography. Only a handful of reports exist regarding its application in pediatric patients. Most of them do not encompass its use in acute appendicitis [19].

This work aimed to investigate and assess the hypothesis that the use of a modified clinical grading judgment and Tissue Harmonic Imaging ultrasonography (THI), as a modified score-aided diagnosis; MCPGS may improve the accuracy in the diagnosis of children with equivocal pictures of acute appendicitis and to compare these results with those of previously published data of CPGS $[1,2]$.

\section{Patients and Methods}

This two centers study was carried out during the period from December 2000 to December 2009. Data of pediatric patients with suspected acute appendicitis who underwent the clinical judgment and US score aided CGPS were reviewed; this data was published before [1].

This was a modification of previously published scoring methods [2,3] including certain subjective clinical parameters measured as 1 point such as fever of 38 , anorexia and vomiting, tachycardia of more than 120 beats/minute. Abdominal pain parameters were also measured with special emphasis on guarding or rigidity, positive per-rectal examinations, however, positive rebound tenderness was given 3 points in this score method as well as other clinical, laboratory and harmonic US measurements (Table 1).

Two hundred sixty five (265) pediatric patients were the core of our current study. In those patients; the proposed usage of THI, clinical judgment and practice as a modified score aided system MCPGS was applied.

The MCPGS with twenty five variables including harmonic ultrasound (US) examination and a marker of inflammatory response was assessed in multivariate analysis using the finding of acute appendicitis at operation as the end point were enrolled in this study (Table 2). Exclusion criteria included those who were proved to have other causes of acute abdominal pain rather than acute appendicitis.

Ultrasonography was performed using linear and curved transducers with ultrasound frequencies ranged between 2.5 and $7.5 \mathrm{MHz}$, commercially available ultrasound systems (Siemens Sonoline Elegra, Germany). The examination was performed with both conventional and THI- US. Scanning parameters were optimized for each method, and all images were obtained with use of the same focal zone. A cine playback mode was used to obtain identical images in two standard planes, longitudinal and transverse scans. Images were obtained with the two methods in random sequence to facilitate their masking for the observers. Harmonic images were acquired at a transmitting frequency of $2.0 \mathrm{MHz}$ and a receiving harmonic bandwidth of $4.0 \mathrm{MHz}$. Conventional US images were obtained at a frequency of 3.5 $\mathrm{MHz}$, which is the commonly used frequency at abdominal imaging in adults. The harmonic and conventional US modes were switched by means of a toggle switch on the scanner control panel. In both the previous CPGS and the current MCPGS rationale of active watchful waiting in suspected appendicitis was a prudent and safe strategy with the use of at least one time repetition of conventional US or THI- US with no increase in the risk of perforation (Figures 1,2,3). All appendices were routinely sent for histopathological examination.

Collected data were statistically analyzed using $\chi^{2}$ test. Continuous variables were analyzed using student's $t$ test. $P \leq 0.5$ were considered statistically significant. Sensitivity and specificity were calculated for the CPGS. Kappa test was used to verify the specificity. All calculations were performed using SAS version 8.2.

\section{Results}

In the current studied group of patients; age and sex analysis shows that cases with and without appendectomy are similar and there is no aggregation of cases in a certain age group or in a certain sex (Table 3). In 187 
Table 1 Clinical Practice Guideline Scoring System (CPGS) [1]:

\begin{tabular}{|c|c|c|c|c|c|}
\hline & & & 1 & 0 & Score \\
\hline \multirow[t]{15}{*}{ Clinical data } & General & - Fever & Yes & No & \\
\hline & & $-H R$ & $>120 / \mathrm{min}$ & $<120 / \mathrm{min}$ & \\
\hline & & - Vomiting & Yes & No & \\
\hline & & - Dehydration & Yes & No & \\
\hline & Abdominal & Abd. pain & & & \\
\hline & & - Localized & Yes & No & \\
\hline & & - History of similar - attacks & No & Yes & \\
\hline & & - Character & Constant & Intermittent & \\
\hline & & - Severity & Intolerable & Tolerable & \\
\hline & & - Course & Progressive & Regressive & \\
\hline & & - Relief by antispasmodic & No & Yes & \\
\hline & & - Bowel Habit alteration & Yes & No & \\
\hline & & - Rebound tenderness & Yes (3) & No & \\
\hline & & - Guarding or rigidity & Yes & No & \\
\hline & & - +ve P.R. examination & Yes & No & \\
\hline \multirow[t]{7}{*}{$\underline{\text { Investigations }}$} & Laboratory & - WBCs leukocytosis & Yes & No & \\
\hline & & - Urine analysis (Findings of UTI) & Yes & No & \\
\hline & Focused abdominal U.S. & - Appendicitis or mass & Yes & No & \\
\hline & & - +ve findings in female Adnxae & No & Yes & \\
\hline & & - +ve findings in liver, Gall bladder, billiary passages & No & Yes & \\
\hline & & - +ve findings kidneys & No & Yes & \\
\hline & & - Free fluid & Yes & No & \\
\hline
\end{tabular}

Total score

Interpretation of results:

$21-15=$ highly suggestive of appendicitis.

$14-8=$ Patient needs repeated evaluation for conclusive result.

$7-0=$ the diagnosis of acute appendicitis in not likely.

patients $(70.6 \%)$ appendectomy was performed, out of them 90 patients (48.1\%) showed MCPGS between 15 and 22, those patients were kept with no oral feeding (NPO), intravenous fluid infusion (IV fluid) of appropriate type and amount according to patient's age before undergoing appendectomy. Only 8 out of the total appendectomies $(4.3 \%)$ were normal at histopathological evaluation. The remaining 97 patients (36.6\%) initially showed MCPGS of 8-14. On repeated evaluation every 2 hours for a maximum of 6 times and repetition of THIUS during the repeated evaluation for at least one time, their score progressed to 15 or more [61 patients (62.9\%) with a MCPGS of $15-17,11$ patients $(11.3 \%)$ with MCPGS of 18 , and 25 patients (25.8\%) with MCPGS of 19]. During the observation period, no antibiotics were given in order not to alter the clinical picture. However, antibiotics were started once the diagnosis was confirmed. No false negative cases were recorded when using MCPGS. (Tables 3, 4)

On the other hand, 78 children (29.4\%) did not undergo appendectomy, 48 of them (61.5\%) showed MCPGS of 8 or less at the initial examination, they were referred to the Pediatric Medical Care with no need for surgical interventions. Thirty patients (38.5\%) showed MCPGS between 9 and 14 declining with repeated examinations until their score became definitely 8 or less, they were managed medically. (Tables 5 , 6)

Specificity of MCPGS was higher than that of CPGS, this may be attributed to the use of harmonic US in this modified scoring system that seems to be significantly superior to the conventional grey scale US $90.69 \%$ in group I (Table 5) compared to a specificity of $70.47 \%$ in group II $(Z=5.999, \mathrm{P}<0.01)$. Also the Positive Predictive Value for group II (95.72\%) was significantly higher than that of group I $(\mathrm{Z}=4.727, \mathrm{P}<0.01)$. Applying Kappa analysis revealed the Kappa Measure for over all agreement to be (96.98\%). These results show the high specificity of our finding for the MCPGS. (Figure 4)

\section{Discussion}

Acute appendicitis traditionally has been a clinical diagnosis and remains so to this day. The diagnosis can be difficult to make in many children who may present with typical symptoms or an equivocal physical examination [18].

In our current study, we evaluated the newly advocated modified clinical practice grading score (MCPGS); 
Table 2 Modified clinical practice and harmonic ultrasonographic grading score (MCPGS):

\begin{tabular}{|c|c|c|c|c|c|}
\hline & & & 1 & 0 & Score \\
\hline \multirow[t]{14}{*}{ Clinical data } & General & - Fever & Yes & No & \\
\hline & & $-H R$ & $>120 /$ min. & $<120 /$ min & \\
\hline & & - Vomiting & Yes & No & \\
\hline & Abdominal & Abd. Pain & & & \\
\hline & & - Localized & Yes & No & \\
\hline & & - History of similar - attacks & No & Yes & \\
\hline & & - Character & Constant & Intermittent & \\
\hline & & - Severity & Intolerable & Tolerable & \\
\hline & & - Course & Progressive & Regressive & \\
\hline & & - Relief by antispasmodic & No & Yes & \\
\hline & & - Bowel Habit alteration & Yes & No & \\
\hline & & - Tenderness & Yes & No & \\
\hline & & - Guarding or rigidity & Yes & No & \\
\hline & & $\begin{array}{l}\text { - +ve P.R. } \\
\text { Associated intra- abdomin,. Disease }\end{array}$ & $\begin{array}{l}\text { Yes } \\
\text { No }\end{array}$ & $\begin{array}{l}\text { No } \\
\text { Yes }\end{array}$ & \\
\hline \multirow[t]{10}{*}{ Investigations } & Laboratory & $\begin{array}{l}\text { - High WBCS } \\
\text { - Elevated CRP }\end{array}$ & $\begin{array}{l}\text { Yes } \\
\text { Yes }\end{array}$ & $\begin{array}{l}\text { No } \\
\text { No }\end{array}$ & \\
\hline & & - Urine analysis (Findings of UTI) & No & Yes & \\
\hline & $\begin{array}{l}\text { Tissue Harmonic } \\
\text { U.S. RLQ }\end{array}$ & $\begin{array}{l}\text {-Aperistaltic non- } \\
\text { Compressible blind ended tubular structure }\end{array}$ & Yes & No & \\
\hline & & -Distinct thickened appendicial wall layers & Yes & No & \\
\hline & & - Outer diameter $>6 \mathrm{~mm}$ & Yes & No & \\
\hline & & -Target sign appearance & Yes & No & \\
\hline & & -Appendicolith(s) & Yes & No & \\
\hline & & $\begin{array}{l}\text {-Periappendiceal } \\
\text { fluid collection }\end{array}$ & Yes & No & \\
\hline & & $\begin{array}{l}\text { - Echogenic } \\
\text { Prominent } \\
\text { pericecal fat } \\
\text { Appendicolith }\end{array}$ & Yes & No & \\
\hline & & - +ve findings in female Adnxae & No & Yes & \\
\hline
\end{tabular}

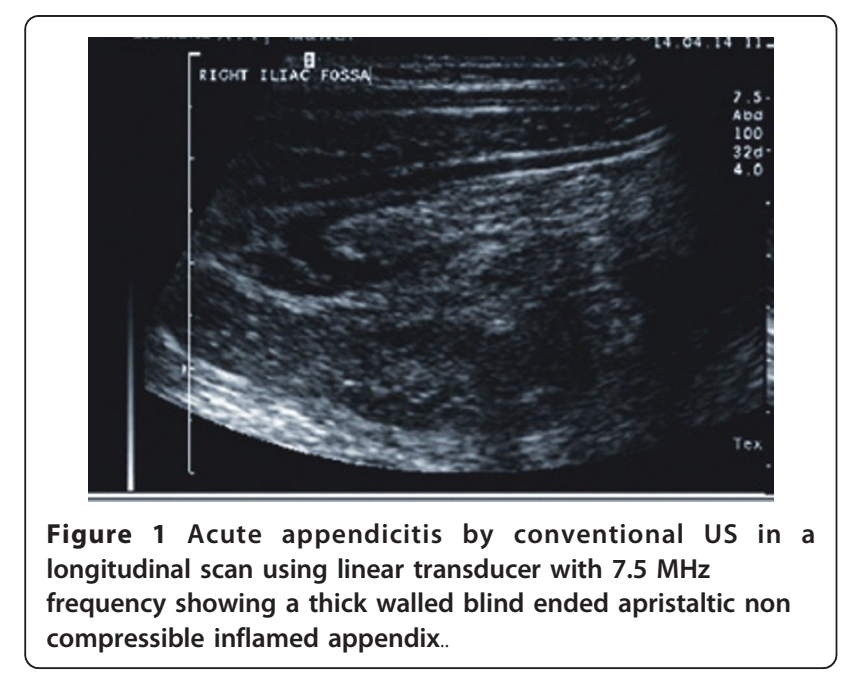

based on clinical judgment, laboratory investigations for inflammatory response and THI- US examination studies in association with the strategy of active watchful waiting performing repeated clinical examinations as well as at least one time repetition of THI before the decision-making process. It was highly accurate in the diagnosis of acute appendicitis in children. The specificity of the MCPGS was $90.69 \%$ compared to a specificity of $70.47 \%$ in the children to whom CPGS and active watchful waiting strategy was applied. In addition, we observed a statistically significant decrease in the negative appendectomy rate in MCPGS compared with those in CPGS.

Our study aimed at avoiding the selection bias mentioned before in similar scoring system [19]. Age and sex analysis shows that cases with and without appendectomy 


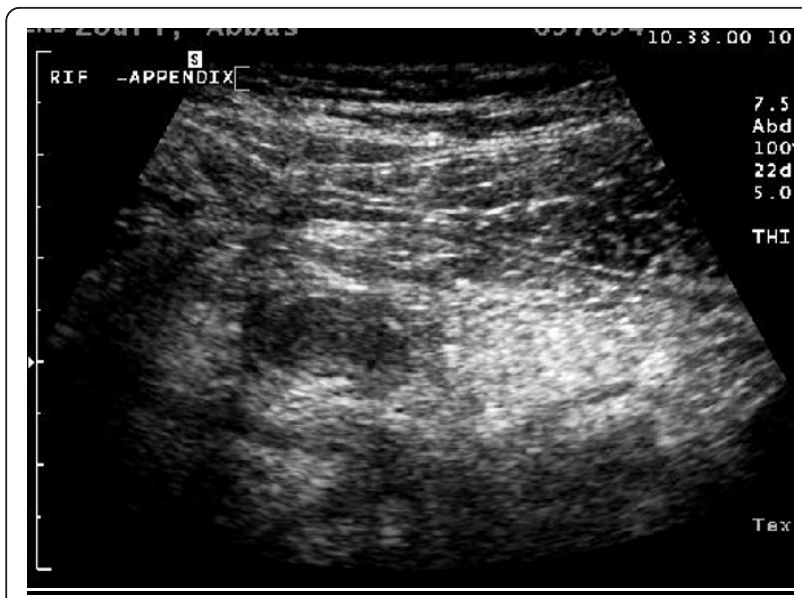

b

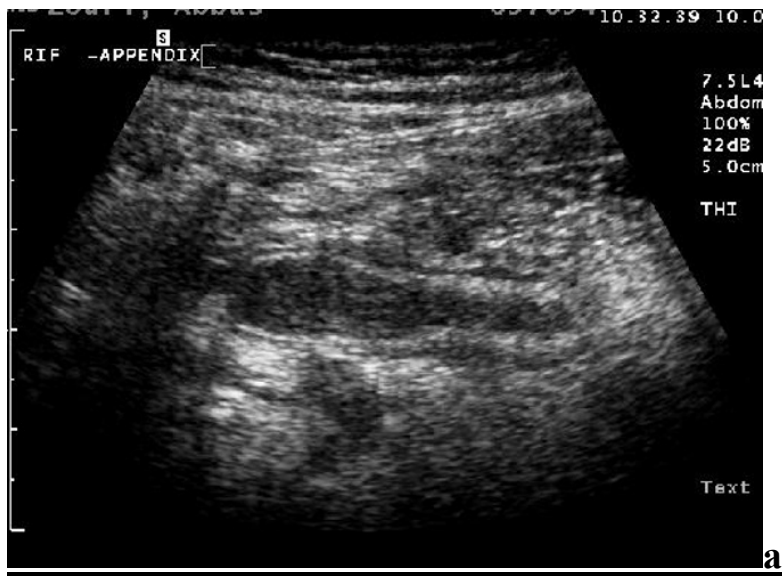

Figure 2 Acute appendicitis by tissue harmonic imaging sonography (THI) using linear transducer with $7.5 \mathrm{MHz}$ revealed: A. Longitudinal scan showing aperistaltic non compressible blind ended tubular structure with distinct thickened wall layers and diameter $>6 \mathrm{~mm}$. B. Transverse scan showing target sign appearance.

are similar and there is no aggregation of cases in a certain age group or in a certain sex. Therefore, the MCPGS can be used at any age and for any sex. Moreover, even those patients who were referred by pediatricians expected to be appendicitis were included as well as self referral that can be appendicitis or not. This illustrates that even if the cases are referred by pediatricians the score can still be used to differentiate cases.

The decrease in negative appendectomies occurred without a rise in the perforation rate. In fact, the

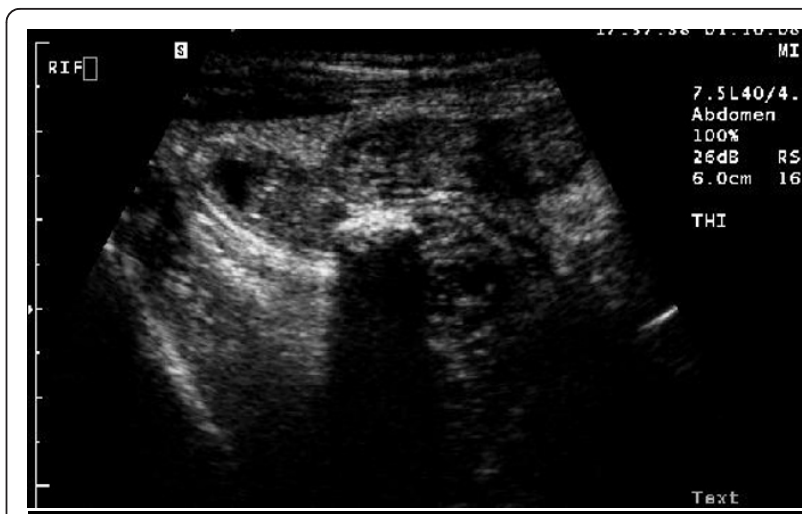

$\mathbf{a}$

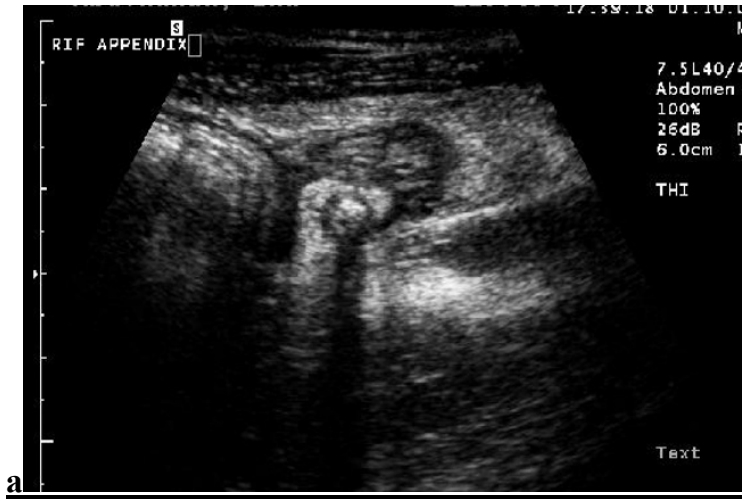

b

Figure 3 Acute appendicitis by tissue harmonic imaging sonography (THI) using linear transducer with 7.5 MHz revealed: A. Longitudinal scan showing a well defined adequately demarcated aperistaltic non compressible blind ended tubular structure with distinct thickened wall layers and diameter $>6 \mathrm{~mm}$ associated with intraluminal curvilinear calcification with posterior acoustic shadowing that reflects an appendicolith. B. Transverse scan showing target sign appearance with the appearance of the appendicolith with its characteristic posterior acoustic shadowing.

perforation rate was lower under the MCPGS, although this change was not significant. Screening ultrasound scanning for pediatric appendicitis has suboptimal accuracy, particularly in obese children with a low likelihood of appendicitis who should not routinely undergo ultrasound scanning. However, when followed by a second ultrasound scanning or a clinical reassessment, it offers high diagnostic accuracy in lean children [20].

Targeted abdominal examination as well as THI constituted around $75 \%$ of our MCPGS scoring system with the aim of increasing its specificity without affecting the system sensitivity. 
Table 3 Characteristics of studied children with clinically suspected appendicitis

\begin{tabular}{|c|c|}
\hline Character & Number (\%) \\
\hline \multicolumn{2}{|l|}{ Age (months) } \\
\hline Minimum-maximum (mean \pm SD) & $\begin{array}{c}18-203(140.63 \pm \\
25.923)\end{array}$ \\
\hline \multicolumn{2}{|l|}{ Gender } \\
\hline Male & $159(60.0 \%)$ \\
\hline Female & $106(40.0 \%)$ \\
\hline \multicolumn{2}{|l|}{ Referring site } \\
\hline None (parent decision) & $229(86.4 \%)$ \\
\hline Health establishment (Pediatrician) & $36(13.6 \%)$ \\
\hline \multicolumn{2}{|l|}{$\begin{array}{l}\text { Duration of symptoms before admission } \\
\text { (hours) }\end{array}$} \\
\hline Minimum-maximum (mean \pm SD) & $6-48(23.15 \pm 11.182)$ \\
\hline \multicolumn{2}{|l|}{ MCPGS* } \\
\hline Minimum-maximum (mean \pm SD) & $1-22(11.54 \pm 6.113)$ \\
\hline \multicolumn{2}{|l|}{ Final Outcome } \\
\hline No surgery & $78(29.4 \%)$ \\
\hline $\begin{array}{l}\text { Appendectomy with negative } \\
\text { histopathology }\end{array}$ & $8(3.0 \%)$ \\
\hline $\begin{array}{l}\text { Appendectomy with positive } \\
\text { histopathology }\end{array}$ & $179(67.6 \%)$ \\
\hline
\end{tabular}

MCPGS = Modified Clinical Practice Guideline Score

In our previously published data [1]; traditional clinical judgment and grey scale US score aided CPGS was performed, 200 patients (75.5\%) underwent appendectomy, of them 35 appendices (17.5\%) were normal at histopathological evaluation. The remaining 65 patients (24.5\%) were discharged from the Pediatric Surgical Facility as not having appendicitis. Yet, out of those 65; 3 children $(4.6 \%)$, ( 2 males and 1 female) were readmitted. US was repeated suggesting acute appendicitis. They underwent appendectomy with positive pathological results. A total of 203 appendectomies (76.6\%) were performed in this CPGS group.
Table 5 Significant predictors of acute appendicitis using forward likelihood multiple logistic models

\begin{tabular}{lccccc}
\hline Predictor & $\beta$ coefficient & Wald test & Exp B & \multicolumn{2}{c}{$\begin{array}{c}95 \% \text { Confidence } \\
\text { Interval }\end{array}$} \\
\cline { 4 - 6 } & & & & LL & UL \\
\hline MCPGS & 0.795 & 50.851 & 2.214 & 1.780 & 2.755 \\
Duration & -0.052 & 3.795 & 0.949 & 0.901 & 1.00 \\
Constant & -5.187 & 25.711 & & & \\
\hline
\end{tabular}

The model succeeded to correctly diagnose $95.5 \%$ of all cases, $97.2 \%$ of the positive cases, and $91.9 \%$ of the negative cases.

$\mathrm{LL}=$ Lower limit of the confidence interval of the odds ratio

UP $=$ Upper limit of the confidence interval of the odds ratio $(\operatorname{Exp} B)$

Moreover, our current results showed the superiority of THI over conventional US for lesion visibility, with THI being preferred over conventional US for $65 \%$ of cases. The findings were clearer and better defined with THI which thereby improved the detection of subtle lesions. Tissue harmonic imaging theoretically improved signal-to-noise ratios by reducing noise from side lobe artifact in the near field and echo detection from multiple scattering events.

This reduced noise was most likely responsible for the superiority of THI over conventional US in the visualization of the findings and improved the confidence of diagnosis for most cases. THI was superior to conventional US in the visualization of lesions containing highly reflective tissues such as fat, calcium and air. It is therefore recommended to be used in obese patients. Better definition of the posterior acoustic shadows in calcifications and appendicolith(s) [21-28].

In our previous study the negative appendectomy rate was $17.5 \%$ compared to $4.3 \%$ in the current work. Contrary to our previous results [1] some published data expressed a negative appendectomy rate of $5.5 \%$ by applying somewhat similar scoring system [19]. The reason for such difference may be their use of computerized tomography scanning (CT) in their system. However, the difference in the negative appendectomy

Table 4 Comparing characteristics of children with and without appendicitis

\begin{tabular}{|c|c|c|c|}
\hline Character & With Appendicitis\# $(n=179)$ & Without Appendicitis $(n=86)$ & Test $(P)$ \\
\hline Age (mean $\pm S D)$ & $141.87 \pm 23.584$ & $138.06 \pm 30.206$ & $t=1.12(0.264)$ \\
\hline Gender & & & $X 2=0.413(0.520)$ \\
\hline Male & $105(58.7)$ & $54(62.8)$ & \\
\hline Female & $74(41.3)$ & $32(37.2)$ & \\
\hline Referring Agent & & & $X 2=0.015(0.903)$ \\
\hline None & $155(86.6)$ & $74(86.0)$ & \\
\hline Pediatrician & $24(13.4)$ & $12(14.0)$ & \\
\hline Duration (mean $\pm \mathrm{SD}$ ) & $22.54 \pm 11.224$ & $24.43 \pm 11.051$ & $Z=1.497(0.134)$ \\
\hline MCPGS $($ mean \pm SD) & $14.82 \pm 4.185$ & $4.72 \pm 3.120$ & $12.393^{*}(<0.001)$ \\
\hline
\end{tabular}

* Significant, $\mathrm{P}<0.05$.

\# include no surgery and surgery with negative histopathology 
Table 6 Diagnostic screening criteria of MCPGS to detect children with acute appendicitis

\begin{tabular}{lccc}
\hline MCPGS & Acute Appendicitis & Free & Total \\
\hline Positive score $(\mathbf{8 +})$ & $179(100.0)$ & $8(9.3)$ & $187(70.6)$ \\
Negative score $(<\mathbf{8 )}$ & $0(0.0)$ & $78(90.7)$ & $78(29.4)$ \\
Total & $179(100.0)$ & $86(100.0)$ & $265(100.0)$ \\
\hline
\end{tabular}

Sensitivity $=100 \%$

Specificity $=90.7 \%$

Positive predictive power $=95.72 \%$

Negative predictive power $=100 \%$

Overall agreement (accuracy) $=96.98 \%$

Kappa $=0.929(P<0.001)$

rate does not support the use of such an expensive sophisticated and hazardous radiological tool to children. CT scanning is not always available in all centers limiting its incorporation in clinical practice guideline scoring system. A recently published study of a practice guideline found that CT scan did not improve the accuracy of diagnosis in patients with suspected appendicitis
[29]. Their guideline did not specifically address the appropriate use of CT scan.

Our MCPGS results, however, did show a great decline in the rate of negative appendectomies. This goes with data of some authors who showed that an imaging protocol using US followed by CT in their patients with equivocal presentations improved the accuracy of diagnosis of appendicitis [30].

We presented our results of MCPGS which evolved from this and other studies recommending ultrasound as the imaging modality of choice in most patients. In addition the recommendation of MCPGS was not limited to imaging alone. Most clinical practice scoring guidelines encourage, but do not require complaints with recommendations [31]. Measuring complaints can be challenging because scoring guidelines can include numerous recommendations and because patients, especially children do not always match preconceived scenarios [32]. Although many barriers limit physician acceptance of scoring guidelines [33], the compliance with our MCPGS is consistent with other developed

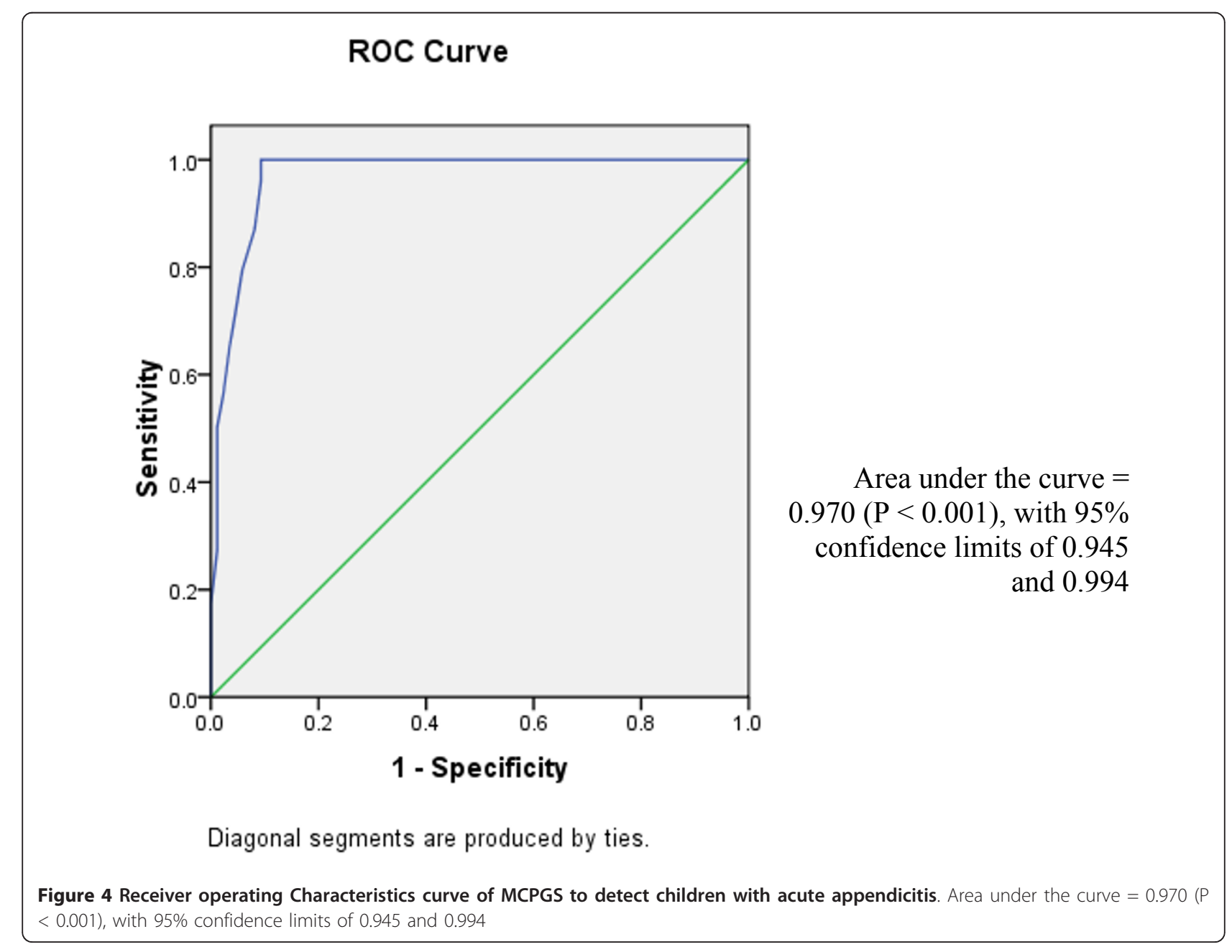


practice scoring guidelines [2,3,6-9,34]. A considerable portion of the improvement seen in our study could be because of the utilization and accuracy of suitable imaging.

Practice scoring guidelines and clinical pathways have been implemented for many conditions [26], including acute appendicitis $[16,30,35]$. Analysis of such guidelines can focus on any combination of patient outcome, resource utilization or complaints with recommendation [16,34-38].

Although most appendicitis scoring guideline and pathways focus on decreasing postoperative treatment cost, a few concentrate diagnosis itself. One such pathway in a pediatric hospital achieved a significant reduction in the number of laboratory tests and X-rays without adversely affecting the incidence of negative appendectomies or perforation [34].

In our proposed MCPGS we included the minimum necessary laboratory investigations to measure the inflammatory response and time and effort saving tissue harmonic abdominal ultrasound scan in order to decrease the probabilities of misdiagnosing acute abdominal pain due to other reasons as acute appendicitis.

In our previous and current studies; all patients underwent the active watchful waiting strategy. This excludes that the decision-making process did result strictly from the MCPGS, and was not rather based on the repeated clinical re-evaluation that was adopted also on CPGS. This exactly shows that our proposed score is superior to the real life common clinical practice.

It may be concluded that the use of a modified clinical and THI ultrasonographic grading score (MCPGS) with the rationale of active watchful waiting in suspected appendicitis with at least one time repetition of THI-US was a prudent and safe strategy. It may improve the accuracy of diagnosing acute appendicitis in the pediatric population as it is superior to the real life common clinical practice.

It leads to fewer negative appendectomies compared with those children to whom it was not applied or other scoring systems were applied as the CPGS with the same strategy of active watchful waiting and repeated US, without a significant change in the perforation rate. Moreover, inpatient observation for serial examinations was reduced significantly. Our clinical practice grading scores can have considerable impact on the diagnosis of acute appendicitis in children. A larger cohort is necessary to validate our findings.

\section{Acknowledgements}

We would like to acknowledge Dr Essam Abd El Bari and Dr. M Yasser Ibrahim for their assistance in revising the manuscript.

\section{Author details}

'Division of Pediatric Surgery, Departments of Surgery, Faculty of Medicine, Suez Canal University, Ismailia, Egypt. ${ }^{2}$ Sporting Students' Health Insurance Hospital, Alexandria, Egypt. ${ }^{3}$ Department of Surgery Faculty of Medicine, Meoufyia University, Egypt. ${ }^{4}$ Department of Radiology, Faculty of Medicine, Suez Canal University, Ismailia, Egypt. ${ }^{5}$ Department of Radiology, Students' Hospital Alexandria University, Egypt.

\section{Authors' contributions}

OMZ has inspired the idea, collected the data and created the analysis and wrote most of the manuscript. TAS helped in collecting the data, analysis and writing of the manuscript. THK and TW have performed the sonography, collected the data and helped on manuscript writing. All authors read and approved the final manuscript.

\section{Competing interests}

The authors declare that they have no competing interests.

Received: 8 September 2011 Accepted: 16 November 2011 Published: 16 November 2011

\section{References}

1. Zakaria OM, Adly OA, El-Labban GA, Khalil HT: Acute Appendicitis In Children: A Clinical Practice Guideline Scoring System. Suez Canal Univ Med J 2005, 8:20-26.

2. François $Y$, Bonvoisin $S$, Descos $L$, Vignal J: Prospective study of a predictive scoring system for the diagnosis of appendicitis in patients with right lower quadrant pain. Long-term outcome]. Gastroenterol Clin Biol 1991, 15:794-799.

3. Samuel M: Pediatric appendicitis score. J Pediatr Surg 2002, 37:877-881.

4. Rezak A, Abbas HM, Ajemian MS, Dudrick SJ, Kwasnik EM: Decreased use of computed tomography with a modified clinical scoring system in diagnosis of pediatric acute appendicitis. Arch Surg 2011, 146:64-67.

5. Dado G, Anania G, Baccarani U, Marcotti E, Donini A, Risaliti A, Pasqualucci A, Bresadola F: Application of a clinical score for the diagnosis of acute appendicitis in childhood: A retrospective analysis of 197 patients. J Pediatr Surg 2000, 35:1320-1322.

6. Escribá A, Gamell AM, Fernández Y, Quintillá JM, Cubells CL: Prospective validation of two systems of classification for the diagnosis of acute appendicitis. Pediatr Emerg Care 2011, 27:165-169.

7. Shera AH, Nizami FA, Malik AA, Naikoo ZA, Wani MA: Clinical scoring system for diagnosis of acute appendicitis in children. Indian J Pediatr 2011, 78:287-290.

8. Shreef KS, Waly AH, Abd-Elrahman S, Abd Elhafez MA: Alvarado score as an admission criterion in children with pain in right iliac fossa. Afr J Paediatr Surg 2010, 7:163-165.

9. Bhatt M, Joseph L, Ducharme FM, Dougherty G, McGillivray D: Prospective validation of the pediatric appendicitis score in a Canadian pediatric emergency department. Acad Emerg Med 2009, 16:591-596.

10. Neilson IR, Laberge JM, Nguyen LT, Moir C, Doody D, Sonnino RE, Youssef S, Guttman FM: Appendicitis in children: Current therapeutic recommendations. J Pediatr Surg 1990, 25:1113-1116.

11. Pearl RH, Hale DA, Molloy M, Schutt DC, Jaques DP: Pediatric appendectomy. J Pediatr Surg 1995, 30:173-178.

12. Körner $H$, Söndenaa $K$, Söreide JA, Andersen $E$, Nysted $A$, Lende $T H$, Kjellevold KH: Incidence of acute nonperforated and perforated appendicitis: Age-specific and sex-specific analysis. World J Surg 1997, 21:313-317.

13. Stephen AE, Segev DL, Ryan DP, Mullins ME, Kim SH, Schnitzer JJ, Doody DP: The diagnosis of acute appendicitis in a pediatric population: To CT or not to CT. J Pediatr Surg 2003, 38:367-371.

14. Partrick DA, Janik JE, Janik JS, Bensard DD, Karrer FM: Increased CT scan utilization does not improve the diagnostic accuracy of appendicitis in children. J Pediatr Surg 2003, 38:659-662.

15. Flum DR, Koepsell $\mathrm{T}$ : The clinical and economic correlates of misdiagnosed appendicitis: Nationwide analysis. Arch Surg 2002. 137:799-804.

16. Putnam TC, Gagliano N, Emmens RW: Appendicitis in children. Surg Gynecol Obstet 1990, 170:527-532. 
17. Emil S, Laberge JM, Mikhail P, Baican L, Flageole H, Nguyen L, Shaw K: Appendicitis in Children: A Ten-Year Update of Therapeutic Recommendations. J Pediatr Surg 2003, 38:236-242.

18. Zielke A, Sitter H, Rampp T, Bohrer T, Rothmund M: Clinical decisionmaking, ultrasonography, and scores for evaluation of suspected acute appendicitis. World J Surg 2001, 25:578-584.

19. Emil S, Mikhail P, Laberge JM, Flageole H, Nguyen LT, Shaw KS, Baican L, Oudjhane K: Clinical versus sonographic evaluation of acute appendicitis in children: A comparison of patient characteristics and outcomes. J Pediatr Surg 2001, 36:780-783.

20. Schuh S, Man C, Cheng A, Murphy A, Mohanta A, Moineddin R, Tomlinson G, Langer JC, Doria AS: Predictors of non-diagnostic ultrasound scanning in children with suspected appendicitis. J Pediatr 2011, 158:112-118

21. Smink DS, Finkelstein JA, Garcia Peña BM, Shannon MW, Taylor GA, Fishman SJ: Diagnosis of Acute Appendicitis in Children Using a Clinical Practice Guideline. J Pediatr Surg 2004, 39:458-463.

22. Perez J, Barone JE, Wilbanks TO, Jorgensson D, Corvo PR: Liberal use of computed tomography scanning does not improve diagnostic accuracy in appendicitis. Am J Surg 2003, 185:194-197.

23. Peña BM, Taylor GA, Fishman SJ, Mandl KD: Effect of an imaging protocol on clinical outcomes among pediatric patients with appendicitis. Pediatrics 2002, 110:1088-1093.

24. Grossman RG, Homer C, Goldman DA: Case 2: Establishing and running a clinical practice guideline program at Children's Hospital, Boston. In Implementing Clinical Practice Guidelines. Edited by: Margolis CZ, Cretin S. Chicago, IL, AHA Press; 1999:151-175.

25. Cretin S: Evaluating and monitoring clinical practice guidelines. In Implementing Clinical Practice Guidelines. Edited by: Margolis CZ, Cretin S. Chicago, IL, AHA Press; 1999:121-138.

26. Cabana MD, Rand CS, Powe NR, Wu AW, Wilson MH, Abboud PA, Rubin HR: Why don't physicians follow clinical practice guidelines? A framework for improvement. JAMA 1999, 282:1458-1465.

27. Grimshaw JM, Russell IT: Effect of clinical guidelines on medical practice: A systematic review of rigorous evaluations. Lancet 1993, 342:1317-1322.

28. Warner BW, Kulick RM, Stoops MM, Mehta S, Stephan M, Kotagal UR: An evidenced-based clinical pathway for acute appendicitis decreases hospital duration and cost. J Pediatr Surg 1998, 33:1371-1375.

29. Firilas AM, Higginbotham PH, Johnson DD, Jackson RJ, Wagner CW, Smith SD: A new economic benchmark for surgical treatment of appendicitis. Am Surg 1999, 65:769-773.

30. Choudhry S, Gorman B, Charboneau JW, Tradup DJ, Beck RJ, Kofler JM, Groth DS: Comparison of Tissue Harmonic Imaging with Conventional US in Abdominal Disease. RadioGraphics 2000, 20:1127-1135.

31. Ward B, Baker AC, Humphrey VF: Nonlinear propagation applied to the improvement of resolution in diagnostic medical ultrasound. J Acoust Soc Am 1997, 101:143-154.

32. Starritt HC, Duck FA, Hawkins AJ, Humphrey VF: The development of harmonic distortion in pulsed finite-amplitude ultrasound passing through liver. Phys Med Biol 1986, 31:1401-1409.

33. Starritt HC, Perkins MA, Duck FA, Humphrey VF: Evidence for ultrasonic finite-amplitude distortion in muscle using medical equipment. J Acoust Soc Am 1985, 77:302-306.

34. Muir TG: Nonlinear effects in acoustic imaging. Acoust Imag 1980 9:93-109.

35. Ragavendra N, Chen H, Powers JE, Nilawat C, Robert JM, Carangi C, LaiferNarin SL: Harmonic imaging of porcine intraovarian arteries using sonographic contrast medium: initial findings. Ultrasound Obstet Gynecol 1997, 9:266-270

36. Wu JY, Shung KK: Nonlinear energy exchange among harmonic modes and its applications to nonlinear imaging. J Acoust Soc Am 1990, 88:2852-2858

37. Siegel S: Nonparametric statistics for the behavioral sciences. New York, NY: McGraw-Hill; 1956, 68-75.

38. Shapiro RS, Wagreich J, Parsons RB, Stancato-Pasik A, Yeh HC, Lao R: Tissue harmonic imaging sonography: evaluation of image quality compared with conventional sonography. AJR Am J Roentgenol 1998, 171:1203-1206.

doi:10.1186/1749-7922-6-39

Cite this article as: Zakaria et al:: Role of clinical judgment and tissue harmonic imaging ultrasonography in diagnosis of paediatric acute appendicitis. World Journal of Emergency Surgery 2011 6:39.

\section{Submit your next manuscript to BioMed Central and take full advantage of:}

- Convenient online submission

- Thorough peer review

- No space constraints or color figure charges

- Immediate publication on acceptance

- Inclusion in PubMed, CAS, Scopus and Google Scholar

- Research which is freely available for redistribution

Submit your manuscript at www.biomedcentral.com/submit
Biomed Central 